\title{
Influence of Water Concentration in the Viscosities and Densities of Cellulose Dissolving Ionic Liquids. Correlation of viscosity data
}

\author{
Cristina Jiménez de la Parra ${ }^{1}$, Johnny R. Zambrano ${ }^{2,3}, \underline{\mathrm{M}}^{\mathrm{a}}$ Dolores Bermejo ${ }^{1 *}$, Ángel \\ Martín ${ }^{1}$,José J. Segovia ${ }^{2}, \mathrm{M}^{\mathrm{a}}$ José Cocero $^{1}$ \\ ${ }^{1}$ High Pressure Process Group, Departmento of Chemical Engineering and \\ Environmental Technology, University of Valladoid, Spain \\ ${ }^{2}$ Research Group TERMOCAL, Thermodynamics and Calibration, University of \\ Valladolid, Escuela de Ingenierias Industriales, Paseo del Cauce 59, E- \\ 47011 Valladolid, Spain \\ ${ }^{3}$ Escuela Politécnica Nacional, Facultad de Ingeniería en Geología y Petróleos, \\ Departamento de Petróleos, Ladrón de Guevara E11-253, Quito, Ecuador \\ ${ }^{*}$ Corresponding autor. Email: mdbermejo@iq.uva.es \\ Tel.: +34983184077 \\ Fax: + 34983184865
}

Keywords: Ionic liquid, Water, Density, Viscosity, Imidazolium Chloride, Imidazolium Acetate,

\begin{abstract}
The densities and viscosities of aqueous mixtures of two cellulose dissolving ionic liquids: 1-allyl-3-methylimidazolium chloride and 1-ethyl-3-methyl imidazolium acetate ionic liquids have been experimentally determined for water concentration up to approx. 35\% water at atmospheric pressure and temperature range from 298.15 to $373.15 \mathrm{~K}$. Molar excess volumes were calculated, resulting in negative values. Literature viscosity correlations were modified in order to describe the viscosity as a function of temperature and water concentration for both water concentrations lower than $\mathrm{x}_{\mathrm{H} 2 \mathrm{O}}=0.4$ and for all the water concentration range. These modified equations were applied to correlate viscosity of water + ionic liquid viscosity data for other 1-alkyl-3methylimidazolium chloride ionic liquids as well as for ethanol +1 -ethyl-3-methyl imidazolium acetate from literature obtaining a good reproducibility of the data.
\end{abstract}

\section{Introduction}

It is well known 1-alkyl-3-methylimidazolium (-mim) ionic liquids (ILs) with chloride (Cl) and acetate (Ac) anions are susceptible to dissolve cellulose and other natural polymers allowing their green processing [1]. Nevertheless the high viscosity of ionic liquids in general and of those with a chloride anion in particular is a limitation for these processes, and, what it is more, their viscosity is increased when cellulose or other polymer is dissolved in the IL presenting even non-newtonian behavior [2]. Nevertheless, for many of these processes other molecular solvents are added to the mixture: i.e. water and sometimes acids for hydrolysis process are added in amounts low enough to prevent cellulose precipitation [2], or in higher amounts to finally precipitate the cellulose or cellulose derived polymers [1]. And it is known that viscosity of ionic liquids is in general decreased with increasing concentrations of molecular solvents such as water or organic solvents [3].

In literature there are several density and viscosity data of imidazolium chloride ionic liquids mixtures with water and other molecular solvents such as: densities of ethanediol + 1-butyl-3methylimidazolium chloride $\left(\mathrm{C}_{4} \mathrm{mimCl}\right)$ from 298 to $318 \mathrm{~K}$ [4]. In the case of water: densities of binary systems water + 1-butyl, 1-hexyl and 1-octyl-3methylimidazolium chloride $\left(\mathrm{C}_{4} \mathrm{mimCl}\right.$, $\mathrm{C}_{6} \mathrm{mimCl}, \mathrm{C}_{8} \mathrm{mimCl}$ ) were determined in the temperature range from 298 to $308 \mathrm{~K}$ using the 
vibrating tube densimeter [ 5]. Rebelo and co-workers [6] measured the densities and speed of sound of $\mathrm{C}_{8}, \mathrm{C}_{10}$ and $\mathrm{C}_{12}$-mimCl ILs in diluted aqueous solutions at temperature range from 283.15 to $313.15 \mathrm{~K}$ to prove the self aggregation phenomena of long chained alkylimidazolium chloride ILs. Gómez et al [ 7] determined densities and viscosities of mixtures water $+\mathrm{C}_{4}, \mathrm{C}_{6}$ and $\mathrm{C}_{8}-\mathrm{mimCl}$ ILs at temperatures from 298.15 to $343.15 \mathrm{~K}$. Liu et al [8] studied densities and viscosities of binary mixtures water + 1-butyl-3-methylimidazolium Chloride $\left(\mathrm{C}_{4} \mathrm{mimCl}\right)$ +water at $298 \mathrm{~K}$. Sing \& Kumar [ 9] determined densities and viscosities of diluted aqueous solutions $\mathrm{C}_{4} \mathrm{mimCl}$ and $\mathrm{C}_{8} \mathrm{mimCl}$ in water. Calvar et al. [10] studied the physical properties of the ternary mixture ehanol+ water $+\mathrm{C}_{4}$ mimCl. To the best of our knowledge densities mixtures water + 1-allyl-3-methylimidazolium chloride (AmimCl) have only been determined at $298 \mathrm{~K}$, viscosities were also determined at this temperature, decreasing both, densities and viscosities with water concentration [ 11]. Viscosities of binary mixtures water + AmimCl and ethanol + AmimCl were determined by Xu et al, observing as well decreased of viscosities with temperature and water molecular solvent concentration [ 12].

In literature several density and viscosity sets of data of binary systems involving ILs of the 1alkyl-3-methylimidazolium acetate (-mimAc) family can be found. Qian et al [13] determined densities and viscosities of 1-methylimidazolium acetate IL and its binary mixtures with alcohols. Araujo et al [14] determined viscosities of $\mathrm{C}_{2}$ mimAc with nucleic acid bases. Quijada et al [15] determined the viscosities and densities of mixtures of water and ethanol with $\mathrm{C}_{2}$ mimAc at temperatures from 298 to $343 \mathrm{~K}$. Romich et al [ 16] determined viscosities and densities of mixtures water $+\mathrm{C}_{2}$ mimAc at temperatures from 293 to $353 \mathrm{~K}$ at water molar fractions higher than 0.34. Fendt et al [18] determined the viscosities of mixtures of $\mathrm{C}_{2} \mathrm{mimAc}$, $\mathrm{C}_{4}$ mimAc and other acetate ILs with water and other solvents such as 1,2-ethanediol, acetonitrile, dimethylformamide at $298 \mathrm{~K}$ using a concentric cylinders viscometer. Hall et al [19] determined the densities and viscosities of pure $\mathrm{C}_{2}$ mimAc and water $+\mathrm{C}_{2}$ mimAc mixtures with high water compositions.

In this work, the density and dynamic viscosity, of different binary mixtures of water and the ionic liquids 1-ethyl-3-methylimidazolium acetate $\left(\mathrm{C}_{2} \mathrm{mimAc}\right)$ and 1-allyl-3-methylimidazolium chloride (AmimCl) at wide temperature and waster molar fractions lower than 0.35 were experimentally determined. From these data, excess molar volumes were determined. Literature correlations were modified to calculate viscosity of the mixtures water + IL as a function of temperature and water concentration for water molar fractions lower than 0.4 and for all the water concentration range. These modified correlations were used to describe the viscosity of binary mixtures of ionic liquids of the same families with water and with ethanol.

\section{Experimental}

Materials. The ionic liquids used, 1-ethyl-3-methylimidazolium acetate $\left(\mathrm{C}_{2} \mathrm{mimAc}\right) 95 \%$ purity and 1-allyl-3-methylimidazolium chloride (AmimCl) 98\% purity were purchased by Iolitec. Water ACS reagent was supplied by Sigma Aldrich. Ionic liquids were treated by vacuum evaporation to dry them and to remove the residual volatile impurities at $95^{\circ} \mathrm{C}$ for at least $48 \mathrm{~h}$. Methods and Procedures. Mixture of IL and water were prepared by mass using a highprecision analytical balance Sartorius CP 224S with a reproducibility of $\pm 1 \cdot 10^{-4} \mathrm{~g}$. The binary mixture was completely mixed by using magnetic stirrer and a Branson 3210 ultrasonic bath at room temperature for at least 3h. Karl Fisher titration was used for verify water content in triplicate using KF Mettler Toledo C20 immediately before and after density and viscosity measurements finding significant changes in the water composition. Thus, the average water concentration between the two measured was used. For samples with lower than $10 \%$ mol in water the results presented are the average of the measures obtained with several samples.An Anton Paar (model SVM 3000) automated rotational Stabinger viscometer and vibrating tube densimeter was used to carry out the measurements of viscosity and density of IL + water 
binary mixtures in a wide range at atmospheric pressure. With this apparatus measurements can be done from 233.15 to $373.15 \mathrm{~K}$ in a viscosity range from $0.2 \mathrm{mPa} \cdot \mathrm{s}$ to $20,000 \mathrm{mPa} \cdot \mathrm{s}$ and in a density range from $0.65 \mathrm{~g} \cdot \mathrm{cm}^{-3}$ to $2 \mathrm{~g} \cdot \mathrm{cm}^{-3}$. The standard uncertainty of the temperature is \pm $0.02 \mathrm{~K}(\mathrm{k}=1)$ from (278.15 to 343.15$) \mathrm{K}$. The relative uncertainty of the dynamic viscosity is \pm $0.5 \%(\mathrm{k}=1)$, and the standard uncertainty of the density is $\pm 0.0005 \mathrm{~g} \cdot \mathrm{cm}^{-3}(\mathrm{k}=1)$. The SVM 3000 Stabinger viscometer has a cylindrical geometry, and it is based on a modified Couette principle with a rapidly rotating outer tube and an inner measuring bob that rotates more slowly. The SVM 3000 apparatus also has a density measuring cell that employs the oscillating U-tube principle. Both density and viscosity cells are filled in one cycle, and the measurements are carried out simultaneously.

\section{Results}

Results of the viscosity and density of $\mathrm{C}_{2}$ minAc and $\mathrm{AmimCl}$ are presented in tables from 1 to 4.

Table 1. Viscosities of the binary mixtures water + 1-ethyl-3-methylimidazolium acetate

\begin{tabular}{|l|rrrrrr|}
\hline XH20 & 0.072 & 0.102 & 0.132 & 0.188 & 0.266 & 0.355 \\
St Dev. & 0.007 & 0.010 & 0.009 & 0.002 & 0.009 & 0.002 \\
T/K & \multicolumn{7}{|c}{$\mu / \mathbf{m P a} \cdot \mathbf{s}$} \\
298.15 & $124 \pm 3$ & $119 \pm 3$ & $112 \pm 3$ & $100 \pm 2$ & $85 \pm 5$ & $75 \pm 2$ \\
303.15 & $92 \pm 2$ & $89 \pm 2$ & $84 \pm 2$ & $76 \pm 2$ & $66 \pm 2$ & $58 \pm 1$ \\
313.15 & $55.4 \pm 0.2$ & $53.6 \pm 0.2$ & $51.1 \pm 0.2$ & $46.7 \pm 0.2$ & $41.8 \pm 0.2$ & $36.9 \pm 0.1$ \\
323.15 & $35.4 \pm 0.5$ & $34.5 \pm 0.4$ & $33.1 \pm 0.4$ & $30.6 \pm 0.3$ & $27.7 \pm 0.4$ & $24.8 \pm 0.3$ \\
333.15 & $24.3 \pm 0.2$ & $23.8 \pm 0.2$ & $22.9 \pm 0.2$ & $21.4 \pm 0.2$ & $19.5 \pm 0.2$ & $17.7 \pm 0.1$ \\
343.15 & $17.63 \pm 0.06$ & $17.23 \pm 0.06$ & $16.73 \pm 0.06$ & $15.69 \pm 0.05$ & $14.44 \pm 0.05$ & $13.19 \pm 0.05$ \\
353.15 & $13.21 \pm 0.08$ & $12.96 \pm 0.06$ & $12.58 \pm 0.07$ & $11.89 \pm 0.07$ & $11.00 \pm 0.07$ & $10.11 \pm 0.06$ \\
363.15 & $10.28 \pm 0.04$ & $10.09 \pm 0.04$ & $9.82 \pm 0.03$ & $9.32 \pm 0.03$ & $8.67 \pm 0.03$ & $8.00 \pm 0.03$ \\
373.15 & $8.19 \pm 0.03$ & $8.07 \pm 0.03$ & $7.86 \pm 0.03$ & $7.48 \pm 0.03$ & $6.98 \pm 0.02$ & $6.47 \pm 0.02$ \\
\hline
\end{tabular}

Table 2. Densities of the binary mixtures water + 1-ethyl-3-methylimidazolium acetate

\begin{tabular}{c|cccccc}
\hline XH2O & 0.072 & 0.102 & 0.132 & 0.188 & 0.266 & 0.355 \\
St Dev. & 0.007 & 0.010 & 0.009 & 0.002 & 0.009 & 0.002 \\
\hline T/K & \multicolumn{7}{c}{$\mathbf{\rho} / \mathbf{g} \cdot \mathbf{c m}^{-3}$} \\
298.15 & $1.0983 \pm 0.0007$ & $1.0983 \pm 0.0009$ & $1.0988 \pm 0.0005$ & $1.0997 \pm 0.0006$ & $1.1005 \pm 0.0006$ & $1.1018 \pm 0.0005$ \\
303.15 & $1.0953 \pm 0.0007$ & $1.0953 \pm 0.0009$ & $1.0958 \pm 0.0005$ & $1.0966 \pm 0.0005$ & $1.0975 \pm 0.0006$ & $1.0989 \pm 0.0006$ \\
313.15 & $1.0892 \pm 0.0006$ & $1.0892 \pm 0.0006$ & $1.0897 \pm 0.0005$ & $1.0905 \pm 0.0005$ & $1.0914 \pm 0.0005$ & $1.0928 \pm 0.0005$ \\
323.15 & $1.0832 \pm 0.0006$ & $1.0832 \pm 0.0010$ & $1.0837 \pm 0.0005$ & $1.0845 \pm 0.0005$ & $1.0855 \pm 0.0006$ & $1.0868 \pm 0.0005$ \\
333.15 & $1.0772 \pm 0.0006$ & $1.0772 \pm 0.0010$ & $1.0777 \pm 0.0005$ & $1.0785 \pm 0.0005$ & $1.0795 \pm 0.0005$ & $1.0808 \pm 0.0006$ \\
343.15 & $1.0712 \pm 0.0006$ & $1.0713 \pm 0.0008$ & $1.0717 \pm 0.0005$ & $1.0726 \pm 0.0005$ & $1.0735 \pm 0.0005$ & $1.0748 \pm 0.0005$ \\
353.15 & $1.0654 \pm 0.0006$ & $1.0654 \pm 0.0011$ & $1.0659 \pm 0.0005$ & $1.0667 \pm 0.0005$ & $1.0677 \pm 0.0006$ & $1.0689 \pm 0.0006$ \\
363.15 & $1.0595 \pm 0.0006$ & $1.0596 \pm 0.0008$ & $1.0600 \pm 0.0005$ & $1.0608 \pm 0.0005$ & $1.0618 \pm 0.0005$ & $1.0629 \pm 0.0005$ \\
373.15 & $1.0538 \pm 0.0006$ & $1.0539 \pm 0.0008$ & $1.0543 \pm 0.0005$ & $1.0551 \pm 0.0005$ & $1.0560 \pm 0.0005$ & $1.0571 \pm 0.0005$ \\
\hline
\end{tabular}

Table 3. Viscosities of the binary mixtures water + 1-allyl-3-methylimidazolium chloride

\begin{tabular}{|l|r|r|r|r|r|r|r|}
\hline XH2O & 0.045 & 0.091 & 0.126 & 0.152 & 0.193 & 0.267 & 0.335 \\
St Dev. & 0.006 & 0.008 & 0.001 & 0.008 & 0.001 & 0.001 & 0.008 \\
\hline T/K & \multicolumn{7}{|c|}{$\boldsymbol{\mu} / \mathbf{m P a} \mathbf{s}$} \\
\hline 298.15 & $1884 \pm 7$ & $1416 \pm 5$ & $1090 \pm 4$ & $887 \pm 3$ & $697 \pm 2$ & $427 \pm 2$ & $258.7 \pm 0.9$ \\
303.15 & $1137 \pm 4$ & $891 \pm 3$ & $691 \pm 2$ & $580 \pm 2$ & $459 \pm 2$ & $293 \pm 1$ & $184.2 \pm 0.6$ \\
313.15 & $473 \pm 2$ & $392 \pm 1$ & $312 \pm 1$ & $270 \pm 1$ & $221 \pm 1$ & $151 \pm 1$ & $101.0 \pm 0.4$
\end{tabular}




\begin{tabular}{r|r|r|r|r|r|r|r|}
323.15 & $232 \pm 8$ & $196 \pm 3$ & $164 \pm 7$ & $147 \pm 7$ & $121 \pm 3$ & $86 \pm 1$ & $61 \pm 1$ \\
328.15 & $167 \pm 5$ & $144 \pm 2$ & $123 \pm 6$ & $108 \pm 3$ & $91 \pm 3$ & $67.1 \pm 0.8$ & $48.6 \pm 0.8$ \\
333.15 & $124 \pm 3$ & $108 \pm 1$ & $92 \pm 3$ & $84 \pm 3$ & $71 \pm 1$ & $53.1 \pm 0.5$ & $39.3 \pm 0.5$ \\
343.15 & $73 \pm 1$ & $64.9 \pm 0.5$ & $56.3 \pm 1.0$ & $51.7 \pm 1.0$ & $45.0 \pm 0.5$ & $35.0 \pm 0.3$ & $26.8 \pm 0.2$ \\
353.15 & $46.2 \pm 0.4$ & $41.8 \pm 0.3$ & $36.9 \pm 0.4$ & $34.3 \pm 0.4$ & $30.4 \pm 0.3$ & $24.3 \pm 0.2$ & $19.2 \pm 0.1$ \\
363.15 & $31.2 \pm 0.2$ & $28.6 \pm 0.1$ & $25.6 \pm 0.2$ & $24.0 \pm 0.2$ & $21.6 \pm 0.1$ & $17.70 \pm 0.09$ & $14.26 \pm 0.07$ \\
373.15 & $22.21 \pm 0.08$ & $20.53 \pm 0.07$ & $18.58 \pm 0.07$ & $17.60 \pm 0.06$ & $15.98 \pm 0.06$ & $13.37 \pm 0.05$ & $10.98 \pm 0.04$ \\
\hline
\end{tabular}
The standard uncertainty of the temperature is $\pm 0.02 \mathrm{~K}$

Table 4. Densities of the binary mixtures water + 1-allyl-3-methylimidazolium chloride

\begin{tabular}{|l|rr|rr|rr|r}
\hline $\begin{array}{l}\mathbf{X}_{\text {H20 }} \\
\text { Dt } \\
\text { Dev. }\end{array}$ & 0.045 & 0.091 & 0.126 & 0.152 & 0.193 & 0.267 & 0.335 \\
\hline $\mathbf{T} / \mathbf{K}$ & 0.006 & 0.008 & 0.001 & 0.008 & 0.001 & 0.001 & 0.008 \\
298.15 & $\mathbf{\rho} / \mathbf{g} \cdot \mathbf{c m}^{-3}$ & & & & & & \\
303.15 & $1.1459 \pm 0.0005$ & $1.1457 \pm 0.0005$ & $1.1454 \pm 0.0005$ & $1.1453 \pm 0.0005$ & $1.1449 \pm 0.0005$ & $1.1439 \pm 0.0005$ & $1.1430 \pm 0.0005$ \\
313.15 & $1.1369 \pm 0.0005$ & $1.1367 \pm 0.0005$ & $1.1366 \pm 0.0005$ & $1.1364 \pm 0.0005$ & $1.1360 \pm 0.0005$ & $1.1351 \pm 0.0005$ & $1.1344 \pm 0.0005$ \\
323.15 & $1.1310 \pm 0.0006$ & $1.1310 \pm 0.0005$ & $1.1307 \pm 0.0006$ & $1.1306 \pm 0.0006$ & $1.1302 \pm 0.0006$ & $1.1295 \pm 0.0005$ & $1.1286 \pm 0.0006$ \\
328.15 & $1.1282 \pm 0.0006$ & $1.1281 \pm 0.0005$ & $1.1281 \pm 0.0006$ & $1.1279 \pm 0.0006$ & $1.1275 \pm 0.0006$ & $1.1267 \pm 0.0005$ & $1.1258 \pm 0.0006$ \\
333.15 & $1.1254 \pm 0.0006$ & $1.1254 \pm 0.0006$ & $1.1252 \pm 0.0006$ & $1.1250 \pm 0.0006$ & $1.1247 \pm 0.0006$ & $1.1240 \pm 0.0006$ & $1.1230 \pm 0.0006$ \\
343.15 & $1.1199 \pm 0.0005$ & $1.1198 \pm 0.0005$ & $1.1197 \pm 0.0006$ & $1.1195 \pm 0.0006$ & $1.1191 \pm 0.0006$ & $1.1183 \pm 0.0005$ & $1.1174 \pm 0.0006$ \\
353.15 & $1.1144 \pm 0.0005$ & $1.1143 \pm 0.0005$ & $1.1142 \pm 0.0006$ & $1.1139 \pm 0.0005$ & $1.1136 \pm 0.0006$ & $1.1128 \pm 0.0006$ & $1.1118 \pm 0.0005$ \\
363.15 & $1.1088 \pm 0.0007$ & $1.1089 \pm 0.0006$ & $1.1087 \pm 0.0005$ & $1.1084 \pm 0.0005$ & $1.1080 \pm 0.0005$ & $1.1073 \pm 0.0006$ & $1.1063 \pm 0.0005$ \\
373.15 & $1.1036 \pm 0.0005$ & $1.1035 \pm 0.0005$ & $1.1033 \pm 0.0005$ & $1.1030 \pm 0.0005$ & $1.1027 \pm 0.0005$ & $1.1018 \pm 0.0005$ & $1.1009 \pm 0.0005$ \\
\hline
\end{tabular}

It is observed that AmimCl present viscosities almost one order of magnitude higher than $\mathrm{C}_{2}$ mimAc. For both ILs viscosities decrease when increasing temperature and water concentration as described in literature ([3],[ 7][ 8],[ 12], [ 13], [15],[18]).

Densities of AmimCl and $\mathrm{C}_{2}$ mimAc are of the same order of magnitude. In both ionic liquids densities decrease with temperature, but in the case of AmimCl density slightly decrease with the molar fraction of water while in the $\mathrm{C}_{2}$ mimAc density slightly increase with water molar fraction.

Comparison of the measured magnitudes with literature data are presented in figures from 1 to 4. In figure 1 , experimental and literature viscosities of the system water $+\mathrm{C}_{2}$ mimAc are compared. In general measurements are in good agreement with literature data [15]-[18]. At lower temperatures and water concentration discrepancies in viscosity are higher probably due to the high hygroscopicity of the ILs used and the difficulty in keeping the water content constant across the measurement procedure. In figure 2, comparison of measured densities of the binary mixture water $+\mathrm{C}_{2}$ mimAc with those of literature are shown. Even when literature data were determined at different water concentration ranges, the data exhibit the same tendency than the data of Romich et al [16]. Nevertheless density data of the pure $\mathrm{C}_{2}$ mimAc measured by Froba [18] seems slightly higher value than the other data.

In figure 3, experimental viscosities of the system water $+\mathrm{AmimCl}$ are compared to literature data showing important discrepancies. To better compare the data logarithmic scale has been used. At $298 \mathrm{~K}$ the data presented in this work are slightly higher than the tendency of the data presented by $\mathrm{Wu}$ and co-workers [11]. For other temperatures, the data presented in this work present values one order of magnitude higher than the data measured by $\mathrm{Xu}$ et al [12] . In figure 4 , densities presented here for water $+\mathrm{AmimCl}$ mixtures are compared to the data of $\mathrm{Wu}$ and co-workers [11] at $298 \mathrm{~K}$. Both datasets present similar trends, with the exception of Wu's data at $\mathrm{X}_{\mathrm{H} 2 \mathrm{O}}=0$ which present a value slightly higher [11]. 


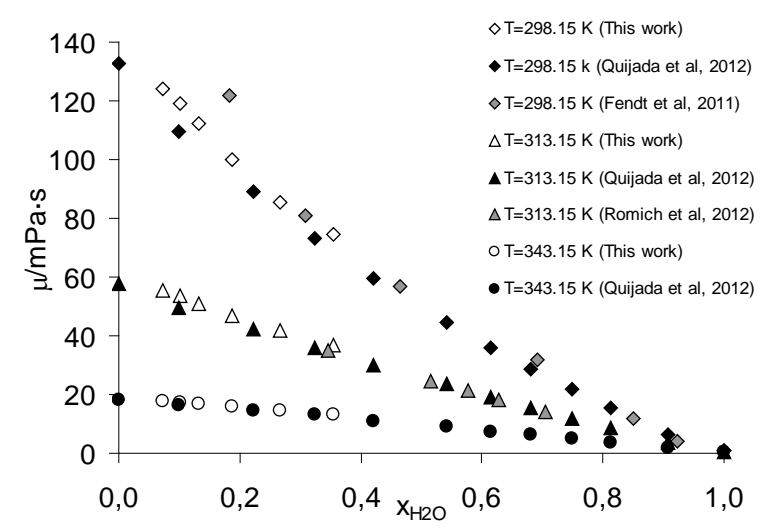

Figure 1. Viscosity of binary mixtures Water $+C_{2} m i m A c$. Comparison to literature data [15], [16] and [17]

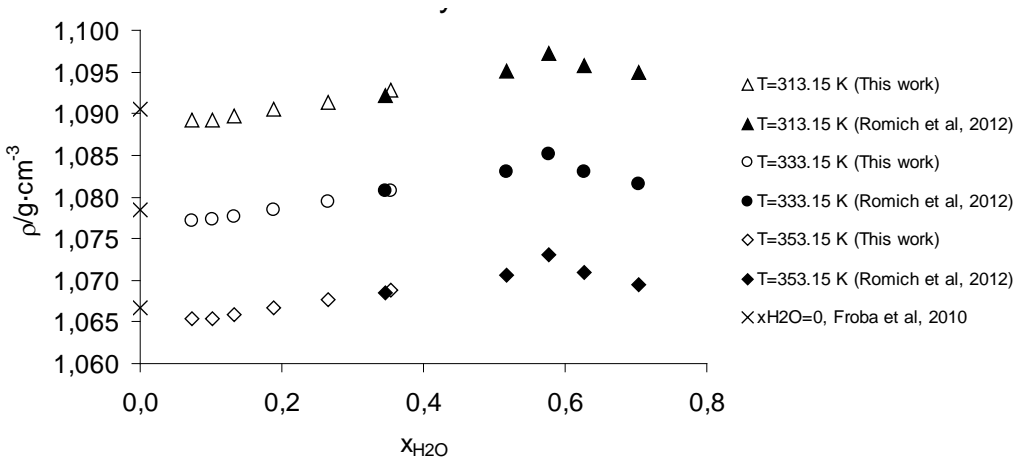

Figure 2. Density of binary mixtures Water $+C_{2} m i m A c$. Comparison to literature data [16], [18]

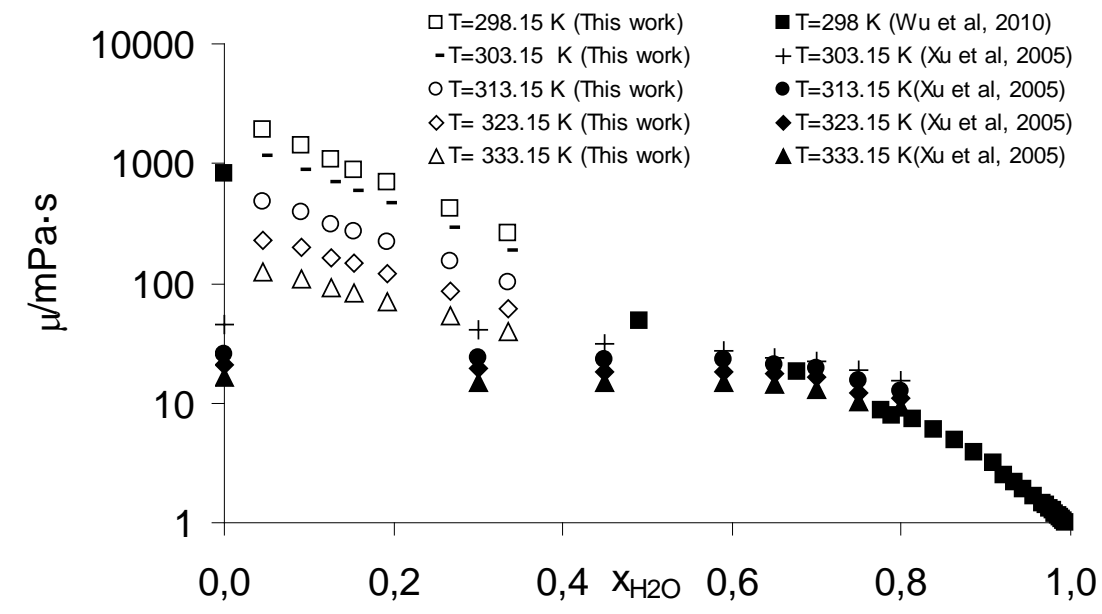

Figure 3. Viscosity of binary mixtures Water + AmimCl. Comparison to literature data [11], [ 12]

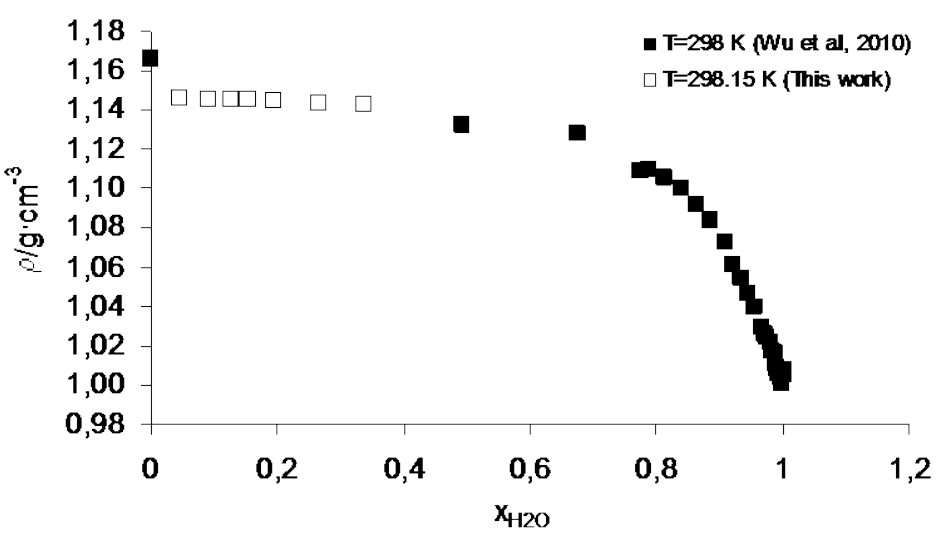


Figure 4. Density of binary mixtures Water + AmimCl. Comparison to literature data [11]

\section{Excess molar volumes}

Excess molar volumes of both water + IL systems were calculated considering the density of the pure ionic liquid as the density measured at the lower water concentration. To cover all the composition range, literature data were used in this calculation ([11], [16]). Results are shown in figure 5. It is observed that excess molar volume is decreasing with increasing water concentration for both ILs reaching a minimum for molar fractions of around 0.6-0.7. Excess molar volumes are more negative for $\mathrm{C}_{2}$ mimAc. The influence of the temperature in the excess molar volumes is negligible. Negative molar volumes indicates that when adding water to the ionic liquid the molar volumes of both liquids are not additives, and the components of the mixture are more closely "packed", and thus the density is higher than the one expected by simple addition of molar volumes. The minimum can be due to hydrogen bonds between water molecules and ionic liquids. At higher concentrations of water excess molar volumes increases again because of the dissociation of the ions forming the ionic liquids [ 7].

The results for the AmimCl are consistent with the results observed Gomez et al [7] with other alkylimidazolium chloride ILs, $\mathrm{C}_{6}$ and $\mathrm{C}_{8} \mathrm{mimCl}$, that presents minimum of around -0.6 $\mathrm{cm}^{3} \mathrm{~mol}^{-1}$ at water concentrations of 0.6 , but present values slightly positives at high water concentration. For these ionic liquids, influence of the temperature is more important than for the ILs considered in this work

In the case of $\mathrm{C}_{2}$ mimAc, more negative excess molar volumes were obtained using the data of Romich et al [16] (-1.6 at $\left.\mathrm{x}_{\mathrm{H} 2 \mathrm{O}}=0.58\right)$ than those obtained by Hall et al [18] (approx $-1 \mathrm{~cm}^{3} \mathrm{~mol}^{-1}$ at $\mathrm{x}_{\mathrm{H} 2 \mathrm{O}}=0.8$ ) for $\mathrm{C}_{2}$ mimAc. Nevertheless, this last work only performs experimental measurements for the pure IL and in the range of water concentrations higher than 0.7. In literature, positive and negative molar volumes has been described. Mokhtarani et al [20] found positive molar volumes for pyridinium based ILs. Rodríguez \& Brennecke [ 23] found negative deviation for $\mathrm{C}_{2}$ mim Ethylsulphate (except at $\mathrm{T}>338 \mathrm{~K}$ and high water content that were slightly positive) and $\mathrm{C}_{2}$ mim Trifluoroacetate and for $\mathrm{C}_{2}$ mim Triflate positive deviations except for $\mathrm{T}<288.15 \mathrm{~K}$ at high water concentrations that were negative. Qian et al [ 14] found negative excess volumes up to $-1 \mathrm{~cm}^{3} \mathrm{~mol}^{-1}$ for methanol in mixtures alcohols + mimAc, for methanol, ethanol and 1-propanol and slightly positive for 1-butanol at very low IL concentration. Thus excess molar volumes are larger for alcohols able to form stronger hydrogen bonds with the IL, forming a better packing. Larger excess volumes of $\mathrm{H}_{2} \mathrm{O}+\mathrm{C}_{2}$ mimAc than those of $\mathrm{H}_{2} \mathrm{O}+$ AmimCl indicate better packing of water with $\mathrm{C}_{2}$ mimAc. Less negative and positive molar volumes are typical of less hydrophilic or hydrophobic ILs.

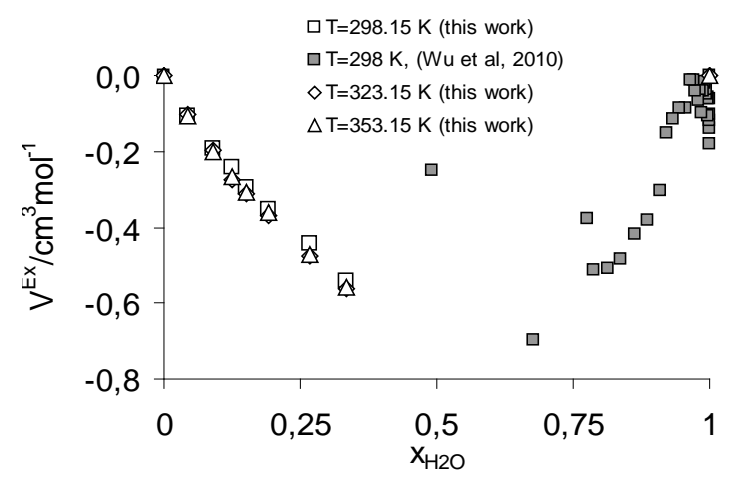

(a)

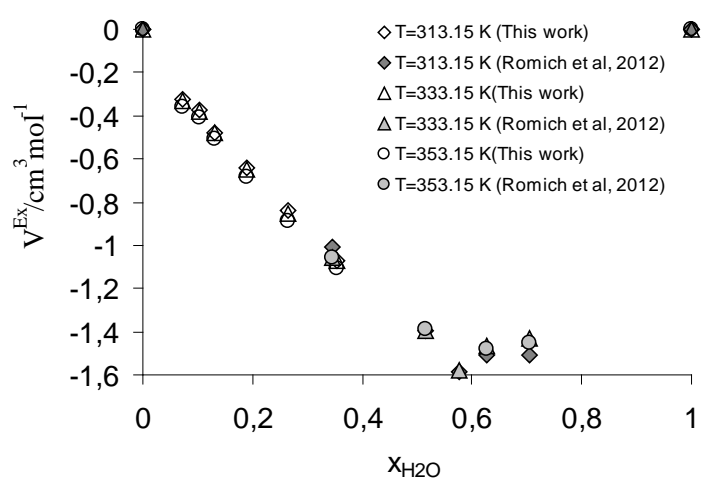

(b)

Figure 5. Excess molar volumes of the systems (a) $\mathrm{H}_{2} \mathrm{O}+\mathrm{AmimCl}$; (b) $\mathrm{H}_{2} \mathrm{O}+\mathrm{C}_{2}$ mimAc calculated using experimental and literature data [11], [16] 


\section{Viscosity correlation}

Several equations have been considered in this work to correlate viscosities of the water + ILs mixtures as a function of temperature and water composition. In first place the expression proposed by Seddon et al [4] for a number of molecular solvents + ILs mixtures (presented in eq. 1) was used.

$$
\mu=\mu_{S} \cdot \exp \left(-x_{C S} / a\right)
$$

Where $\mu_{\mathrm{s}}$ is the viscosity of the pure IL, $\mathrm{x}_{\mathrm{CS}}$ is the molar fraction of the molecular solvent and $A$ is a constant with different values for each IL. This expression was proposed for a constant temperature of $293 \mathrm{~K}$. In this work, the first term was substituted by the well known exponential type equation typical for describing the viscosity dependence with temperature.

$\mu=\exp \left(\frac{A}{T(K)}+B\right)$

Where $\mu$ is the viscosity of the pure IL, T is the temperature in $\mathrm{K}$, and $A$ and $B$ are constant dependent on the IL. Thus, substituting the eq. 2 into eq. 1 , eq. 3 is obtained.

$\mu=\exp \left(\frac{A}{T(K)}+B\right) \cdot \exp \left(-x_{H 2 O} / C\right)$

An addition temperature dependent parameter has been added in order to improve the description of the experimental value was introduced in the equation (3), obtaining eq.4:

$\mu=\exp \left(\frac{A}{T(K)}+B\right) \cdot \exp \left(\frac{x_{H 2 O}}{C+D \cdot T(K)}\right)$

Where $A, B, C$ and $D$ are empirical parameters depending on the IL. These parameters have been adjusted by minimization of the objective function presented in eq.4.

$\operatorname{Obj}=\Sigma\left(\frac{\left|\mu_{\exp }-\mu_{c a l c}\right|}{\mu_{\exp }}\right)$

Parameters, as well as values of the objective function are presented in Table 5.

Table 5. Parameters fitted to the correlations for calculating the viscosities of the aqueous mixtures of AmimCl and C2mimAc

\begin{tabular}{|c|c|c|c|c|}
\hline & \multicolumn{3}{|c|}{$\mu=\exp \left(\frac{E}{T^{2}}+\frac{A}{T}+B\right) \cdot \exp \left(\frac{x_{H 2 O}}{C+D \cdot T}\right)$} & \\
\hline & \multicolumn{4}{|c|}{ Range $\mathrm{x}_{\mathrm{H} 2 \mathrm{O}}<0.4$} \\
\hline IL & \multicolumn{2}{|c|}{$\mathrm{C}_{2}$ mimAc } & \multicolumn{2}{|c|}{$\mathrm{AmimCl}$} \\
\hline A & 4192.4 & -8277.0 & -15114 & 6845 \\
\hline$B$ & -9.192 & 9.542 & 17,65 & $-15,36$ \\
\hline C & 0.9687 & 2.5323 & 0,7839 & 0,3666 \\
\hline $\mathrm{D}$ & $-5.183 E-03$ & $-1.013 \mathrm{E}-02$ & $-3,103 E-03$ & $-1,761 \mathrm{E}-03$ \\
\hline $\mathrm{E}$ & 0 & 2063448 & 3635636 & 0 \\
\hline Av. Dev. & $6.7 \%$ & $1.1 \%$ & $2,5 \%$ & $13 \%$ \\
\hline Max. Dev. & $17 \%$ & $4.7 \%$ & $8.6 \%$ & $43 \%$ \\
\hline \multicolumn{5}{|c|}{$\ln \mu=x_{I L} \cdot\left(\frac{E}{T^{2}}+\frac{A}{T}+B\right) \cdot+x_{H 2 O} \cdot \ln \mu_{H 2 O}+\frac{x_{I L} \cdot x_{H 2 O}}{\left(x_{I L}+F\right)} \cdot(B \cdot T+C)$} \\
\hline \multicolumn{5}{|c|}{ Valid for all the concentration range } \\
\hline A & \multicolumn{2}{|c|}{-8277.0} & \multicolumn{2}{|c|}{-15114} \\
\hline$B$ & \multicolumn{2}{|c|}{-0.01189} & \multicolumn{2}{|c|}{0.01744} \\
\hline
\end{tabular}




\begin{tabular}{|c|c|c|}
\cline { 2 - 3 } \multicolumn{1}{c|}{$C$} & 7.291 & -3.505 \\
\hline$D$ & $-1.013 \mathrm{E}-02$ & $-3.103 \mathrm{E}-03$ \\
\hline $\mathrm{E}$ & 2063448 & 3635636 \\
\hline $\mathrm{F}$ & 0.1382 & 0.2174 \\
\hline Av. Dev. & $3.9 \%$ & $1.3 \%$ \\
\hline Max. Dev. & $33 \%$ & $4.9 \%$ \\
\hline
\end{tabular}

With this equation a good description of the viscosity for water concentration up to $40 \% \mathrm{~mol}$ (the range studied in this work) is achieved, nevertheless at higher water concentrations the behaviour is not lineal with water concentration and a more complex equation must be used. For the $\mathrm{C}_{2}$ mimAc the average relative deviation is of viscosity prediction in the range studied were of $6.7 \%$, being the maximum deviation of $17 \%$ for $\mathrm{T}=373.15 \mathrm{~K}$ and $35.5 \% \mathrm{~mol} \mathrm{H}_{2} \mathrm{O}$ compared to the experimental data presented in this work.

In the case of $\mathrm{AmimCl}$, the better fitting achieved using eq. 4 gives an average relative deviation of $13 \%$ and a maximum relative deviation of $43 \%$ at $\mathrm{T}=373.15 \mathrm{~K}$ and $33.5 \% \mathrm{H}_{2} \mathrm{O}$ compared to the experimental data presented in this work. It is observed that large deviations are observed at low and high water concentrations. The predictions obtained are not good. It is due to the deviation from straight line from the $\ln \mu$ vs $1 / T$ at low water concentrations. To solve this problem a modification was proposed in eq. 4 , in such a way that the term describing the $\ln \mu$ of the "pure" ionic liquid" will consist of a cuadratic expression and not a linear one, obtaining eq. 6 , in which an additional parameter $\mathrm{E}$ is introduced.

$$
\mu=\exp \left(\frac{E}{T^{2}}+\frac{A}{T}+B\right) \cdot \exp \left(\frac{x_{H 2 O}}{C+D \cdot T}\right)
$$

The equation was fitted to the experimental data presented in this work using the expression presented in eq. 5 as objective function. The optimized parameters are presented in Table 5 for both water + IL systems. With the modified equation, prediction of the viscosity could be done with an average relative deviation of $2.5 \%$ and a maximum relative deviation of $8.6 \%$ corresponding to a $\mathrm{T}=298.15 \mathrm{~K}$ and $26.7 \% \mathrm{~mol} \mathrm{H}_{2} \mathrm{O}$ for the system $\mathrm{H}_{2} \mathrm{O}+\mathrm{AmimCl}$. For the system $\mathrm{H}_{2} \mathrm{O}+\mathrm{C}_{2}$ mimAc the average relative deviation was of $1 \%$ and a maximum deviation was of $4.7 \%$ for $35.4 \% \mathrm{~mol} \mathrm{H}_{2} \mathrm{O}$ and $298 \mathrm{~K}$. The predictions together with the experimental data are presented in figure 6 and 7.

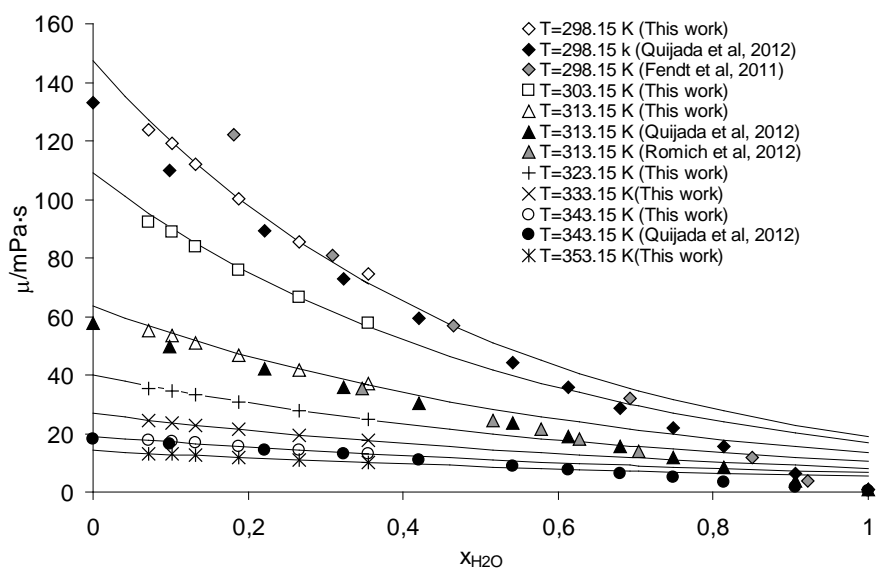

Figure 6. Experimental viscosities of the system $\mathrm{H}_{2} \mathrm{O}+\mathrm{C}_{2}$ mimAc (data from this work, Quijada et al [16] and Fendt et al [18]) and those calculated with equation 6. 


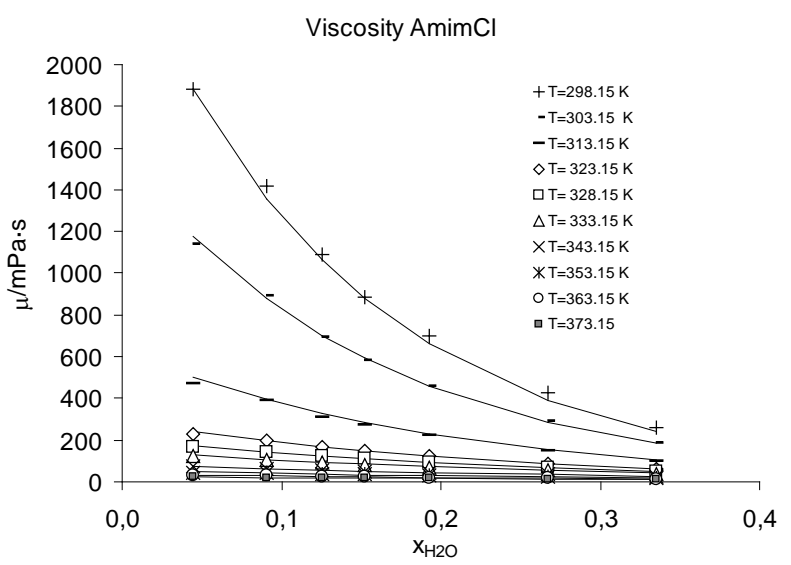

Figure 7. Experimental viscosities of the system $\mathrm{H}_{2} \mathrm{O}+\mathrm{AmimCl}$ and those calculated with equation 6.

The correlation presented is only valid for water molar fractions lower than 0.4. In figure 6 the whole water concentration range has been represented in order to show that at water molar fractions higher than 0.4 the shape of the predicted curve is very different from the tendency of the experimental data. In an attempt to find an expression to calculate viscosity of the mixture $\mathrm{H}_{2} \mathrm{O}+\mathrm{IL}$ in the whole range of concentrations, the well known method of Grunberg and Nissan [24], [25] presented for binary mixtures in eq. 7 has been used.

$\ln \mu=x_{I L} \cdot \ln \mu_{I L}+x_{H 2 O} \cdot \ln \mu_{H 2 O}+x_{I L} \cdot x_{H 2 O} \cdot G_{12}$

Where $\mathrm{x}_{\mathrm{IL}}$ and $\mathrm{x}_{\mathrm{H} 2 \mathrm{O}}$ are the molar fraction of water and IL, $\mu_{\mathrm{H} 2 \mathrm{O}}$ and $\mu_{\mathrm{IL}}$ are the viscosities of the pure compounds and $\mathrm{G}_{12}$ a constant parameter. The first part of this equation (shown in eq. 8) is considered as a kind of ideal viscosity by Hall et al [19] for mixtures ILs + water.

$\ln \mu=x_{I L} \cdot \ln \mu_{I L}+x_{H 2 O} \cdot \ln \mu_{H 2 O}$

The comparison of ideal viscosities with experimenal viscosities in all the concentration range is shown in figure $8 \mathrm{a}$ ) and $\mathrm{b}$ ) for aqueous mixtures of AmimCl and $\mathrm{C}_{2}$ mimAc respectively in thin straight lines. Viscosity of the pure IL the one calculated with eq. 6 respectively for $\mathrm{C}_{2} \mathrm{mimAc}$ and AmimCl using the parameters from table 5. For the system $\mathrm{H}_{2} \mathrm{O}+\mathrm{AmimCl}$, it is observed that at low water concentrations there is a linear relation between $\ln \mu$ and $\mathrm{x}_{\mathrm{H} 2 \mathrm{O}}$, the shape of the curve is curving at high water concentrations. What it is more, the slopes of the experimental data are more different from the ideal ones when the temperature is increasing. In the case of the system $\mathrm{H}_{2} \mathrm{O}+\mathrm{C}_{2}$ mimAc, the system is highly non-ideal as it can be observed in figure 8 (b), ln $\mu$ vs $\mathrm{x}_{2} \mathrm{O}$ is only lineal up $\mathrm{x}_{\mathrm{H} 2 \mathrm{O}}$ around 0.5 , and the slopes are much lower than the ideal ones even at low temperatures.

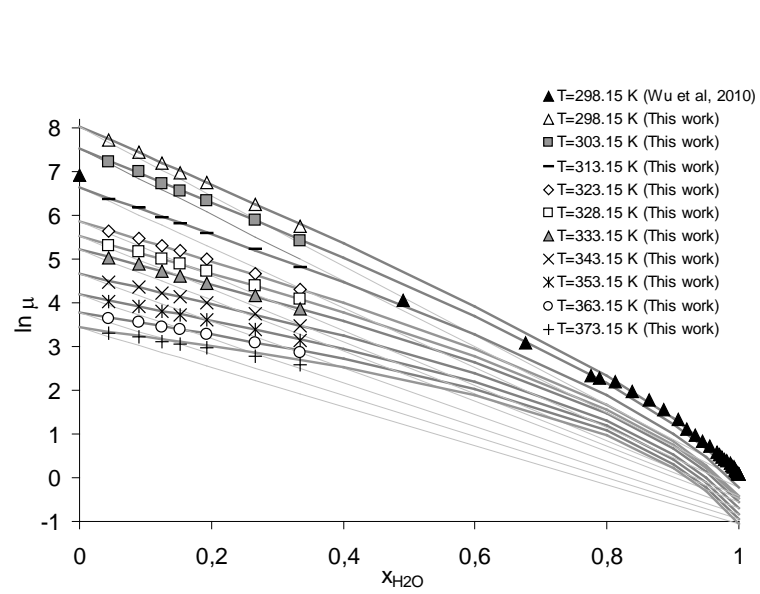

(a)

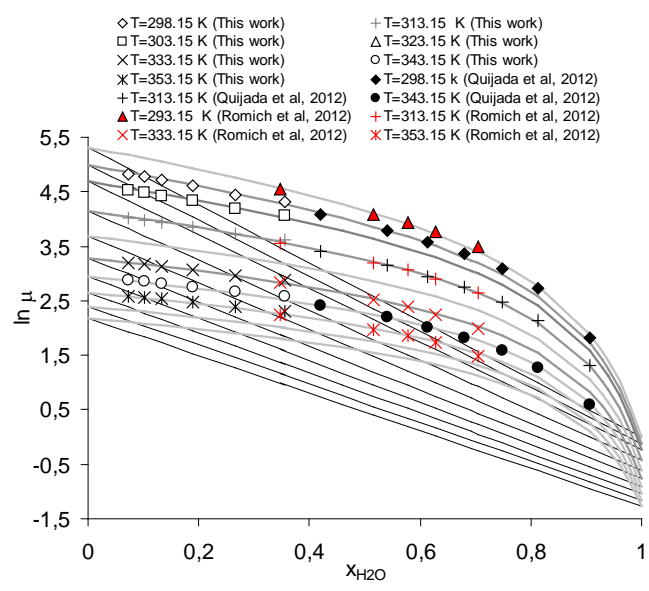

(b) 
Figure 8. Comparison of the experimental data presented in this work and taken from literature (symbols)[12], [16], [17] with the ideal viscosity for the binary systems (thin straight lines), and the viscosity calculated by the Grunberg and Nissan modified equation (thick grey line): a) $\mathrm{H}_{2} \mathrm{O}+$ AmimCl; b) $\mathrm{H}_{2} \mathrm{O}+\mathrm{C}_{2}$ mimAc.

Following equation of 7, the non-idealities can be described by using a term exclusively dependant of the product of molar fractions of both components, but a good description was not achieved in this way. The deviation of the ideality was highly dependant on water molar fraction and on temperature. Thus, a expression of the type shown in eq. 9 was used to fit the viscosities of water + IL mixture in all the concentration range.

$\ln \mu=x_{I L} \cdot\left(\frac{E}{T^{2}}+\frac{A}{T}+B\right) \cdot+x_{H 2 O} \cdot \ln \mu_{H 2 O}+\frac{x_{I L} \cdot X_{H 2 O}}{\left(x_{I L}+F\right)} \cdot(B \cdot T+C)$

Where $A, B, C, D, E$ and $F$ are empirical parameters which optimized values are listed in Table 5 for both water + IL systems. With this equation a good description of the viscosity as a function of temperature and water molar fraction was achieved for all the water concentration range as it can be observed in figure 8. Equation was calculating with an average relative deviation of $1.3 \%$ for the system $\mathrm{H}_{2} \mathrm{O}+\mathrm{AmimCl}$ being the maximum deviation of $4.9 \%$ for $33.5 \%$ water at $363 \mathrm{~K}$, while for the system $\mathrm{H}_{2} \mathrm{O}+\mathrm{C}_{2}$ mimAc, the average relative deviation with respect the experimental data was of $3.9 \%$ and the maximum deviation was of $33 \%$ for $74.8 \% \mathrm{~mol} \mathrm{H}_{2} \mathrm{O}$ at $333.15 \mathrm{~K}$. For the system $\mathrm{H}_{2} \mathrm{O}+\mathrm{C}_{2}$ mimAc, data presented in this work as well as literature data [16],[17] has been used to fit the parameters, while for the system $\mathrm{H}_{2} \mathrm{O}+$ AmimCl, only the experimental data presented here have been used to fit the parameters because the other data set were not consistent with our data. Nevertheless in the figure 8 data for the system $\mathrm{H}_{2} \mathrm{O}+\mathrm{AmimCl}$, the data of Wu et al [12] were plotted in order to check that the equation is able to follow the tendency of the data at higher water concentrations.

Eq. 6 and 9 were used to correlate the viscosity of aqueous mixtures of alkylimidazolium chloride ILs ( $\mathrm{C}_{4} \mathrm{mimCl}, \mathrm{C}_{6} \mathrm{mimCl}$ and $\left.\mathrm{C}_{8} \mathrm{mimCl}\right)$ and of the system Ethanol $+\mathrm{C}_{2} \mathrm{mimAc}$ using literature data [ 8], [16], [26]. For the ionic liquid $\mathrm{C}_{4} \mathrm{mimCl}$ parameters for water concentration lower than $40 \% \mathrm{~mol}$ was not performed because of the lack of consistent data of the system in literature. Viscosities for the pure c4mimCl were correlated using data from Seddon et al [26]. Optimized parameters as well as maximum and average deviations of these binary systems are shown in table 6. Good description of the viscosity of the mixtures is achieved with average deviations lower than $15 \%$ is achieved except in the case of the system $\mathrm{H}_{2} \mathrm{O}+\mathrm{C}_{8}$ mimCl, where average deviations were as high as $23 \%$. Thus, the modified equations can satisfactorily represent the viscosities of aqueous systems involving ionic liquids of the 1-alkyl-3methylimidazolium chloride families and acetate as well as when the co-solvent used is a polar organic solvent such as ethanol. In figure 9 the ideal viscosities as well as the prediction of the modified Grunberg and Nissan equation together with literature data are shown for the above mentioned systems. It is observed that the non-ideality in the viscosity of the mixtures $\mathrm{H}_{2} \mathrm{O}+$ $\mathrm{C}_{\mathrm{n}} \mathrm{mim}$ in increasing with higher number of carbon in the alkyl chain (n), as the viscosity of the real system is becoming more different than those indicated by ideal viscosity. In the case of the system Ethanol $+\mathrm{C}_{2}$ mimAc, it can be observed in figure 9 (a) that when ethanol is used as a cosolvent a behaviour more similar to the ideal is obtained and a larger decrease in viscosity for the same molar fraction of co-solvent, compared to the system $\mathrm{H}_{2} \mathrm{O}+\mathrm{C}_{2}$ mimAc shown in figure 8 b).

Table 6. Parameters fitted to the correlations for calculating the viscosities of the aqueous mixtures of $\mathbf{H 2 O}+\mathbf{C}_{4}, \mathbf{C}_{6}$ and $\mathbf{C}_{8} \mathrm{mimCl}$ and Ethanol $+\mathbf{C}_{2}$ mimAc using literature data [ 8], [16], [26]

$$
\mu=\exp \left(\frac{E}{T^{2}}+\frac{A}{T}+B\right) \cdot \exp \left(\frac{x_{H 2 O}}{C+D \cdot T}\right)
$$




\begin{tabular}{|c|c|c|c|c|}
\hline & \multicolumn{4}{|c|}{ Range $\mathrm{x}_{\mathrm{H} 2 \mathrm{O}}<0.4$} \\
\hline IL & $\mathrm{H}_{2} \mathrm{O}+\mathrm{C}_{4} \operatorname{mimCl}$ & $\mathrm{H}_{2} \mathrm{O}+\mathrm{C}_{6} \operatorname{mimCl}$ & $\mathrm{H}_{2} \mathrm{O}+\mathrm{C}_{8} \operatorname{mimCl}$ & Ethanol $+\mathrm{C}_{2} \operatorname{mimAc}$ \\
\hline A & & -19874.6 & -16573 & -8277 \\
\hline $\mathrm{B}$ & & 24.580 & 19.51 & 9.54 \\
\hline C & & 0.4890 & 0.5420 & 1.0534 \\
\hline $\mathrm{D}$ & & $-2.005 \cdot 10^{-3}$ & $-2.293 \cdot 10^{-3}$ & $-4.347 \cdot 10^{-3}$ \\
\hline$E$ & & 4611723 & 4091355 & 2063448 \\
\hline Av. Dev & & $8.8 \%$ & $10 \%$ & $2.7 \%$ \\
\hline $\operatorname{Max}$ & & $27 \%$ & $32 \%$ & $11 \%$ \\
\hline \multicolumn{5}{|c|}{$\ln \mu=x_{I L} \cdot\left(\frac{E}{T^{2}}+\frac{A}{T}+B\right) \cdot+x_{H 2 O} \cdot \ln \mu_{H 2 O}+\frac{x_{I L} \cdot x_{H 2 O}}{\left(x_{I L}+F\right)} \cdot(B \cdot T+C)$} \\
\hline \multicolumn{5}{|c|}{ Valid for all the concentration range } \\
\hline A & -11065 & -19874.6 & -16573.2 & -8277.0 \\
\hline $\mathrm{B}$ & 10.507 & 24.580 & 19.510 & 9.541 \\
\hline C & 0.005 & 0.00123 & -0.021 & 0.012 \\
\hline $\mathrm{D}$ & -0.234 & 2.161 & 11.023 & -2.057 \\
\hline$E$ & 3245583 & 4611723 & 4091354 & 2063448 \\
\hline $\mathrm{F}$ & 0.1051 & 0.1158 & 0.0499 & 0.3701 \\
\hline Av. Dev. & $4.9 \%$ & $13 \%$ & $23 \%$ & $3.4 \%$ \\
\hline $\operatorname{Max}$ & $22 \%$ & $72 \%$ & $79 \%$ & $9.6 \%$ \\
\hline
\end{tabular}

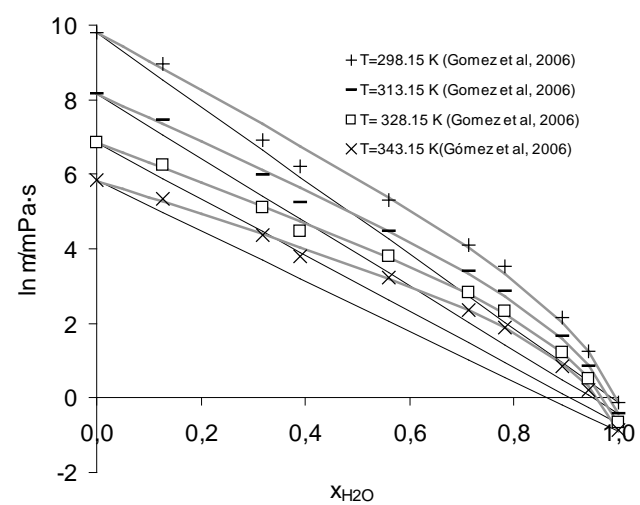

(a) Viscosity $\mathrm{H}_{2} \mathrm{O}+\mathrm{C}_{6}$ mimCl

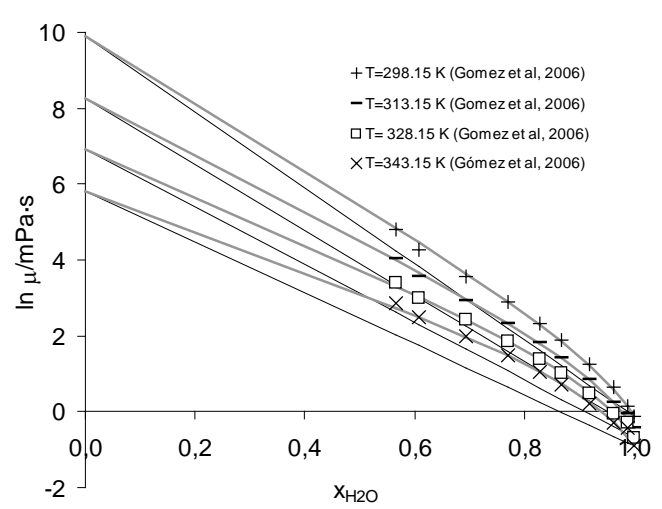

(c) Viscosity $\mathrm{H}_{2} \mathrm{O}+\mathrm{C}_{4}$ mimCl

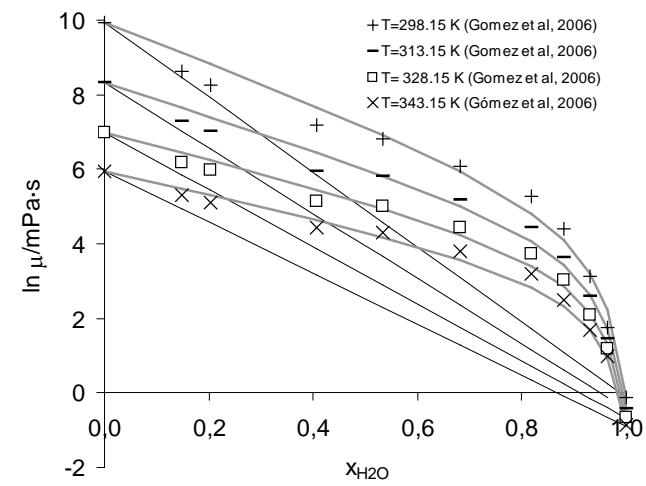

(b) Viscosity $\mathrm{H} 2 \mathrm{O}+\mathrm{C}_{8}$ mimCl

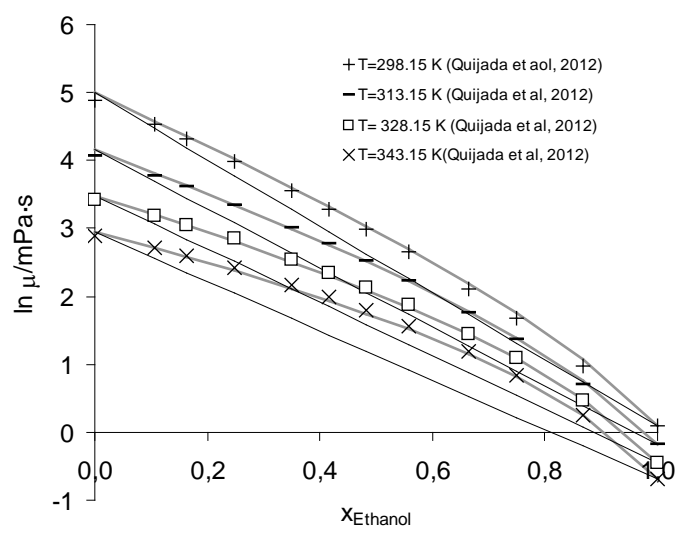

(d) Viscosity Ethanol $+\mathrm{C}_{2}$ mimAc

Figure 9. Comparison of the literature data [ 8], [16] (symbols) with the ideal viscosity for the binary systems (thin straight lines), and the viscosity calculated by the Grunberg and Nissan modified equation (thick grey line): a) $\mathrm{H}_{2} \mathrm{O}+\mathrm{C}_{6}$ mimCl; b) $\mathrm{H}_{2} \mathrm{O}+\mathrm{C}_{8}$ mimCl; c) $\mathrm{H}_{2} \mathrm{O}+\mathrm{C}_{4}$ mimCl; d) Ethanol + $\mathbf{C}_{2}$ mimAc. 


\section{Conclusions}

Densities and viscosities of the systems $\mathrm{H}_{2} \mathrm{O}+1$-allyl-3-methyilimidazolium chloride and $\mathrm{H}_{2} \mathrm{O}+1$-ethyl-3-methylimidazolium acetate were experimentally determined in the temperature range from 298.15 to $373.15 \mathrm{~K}$ and for water molar fractions lower than 0.35 .

Viscosities and densities of the system $\mathrm{H}_{2} \mathrm{O}+1$-ethyl-3-methylimidazolium acetate were consistent with existent literature data. Data of the system $\mathrm{H}_{2} \mathrm{O}+1$-allyl-3methyilimidazolium Chloride, present inconsistencies with the scarce literature data existent.

Excess molar volumes of the mixtures were calculating obtaining negative values, being more negative for the system $\mathrm{H}_{2} \mathrm{O}+1$-ethyl-3-methylimidazolium acetate, what indicates a strongly packed structure attributed to the formation of hydrogen bonds.

Literature equations has been modified in order to correlate the viscosity data a function of temperature and water molar fraction, for both water molar fractions lower than 0.4 and for all the water concentration ranges. Napierian logarithm of viscosities of pure ionic liquids has been correlated as a cuadratic equation instead of the tradicional lineal equations. Seddon and Grunberg and Nissan equations were modified to describe the highly no ideal viscosity behaviour as well as the temperature dependence, obtaining a average deviations lower than $15 \%$ in most systems considered. The equation has been extended successfully to describe the viscosity of other aqueous imidazolium chloride binary systems as well as to the system ethanol + 1-ethyl-3-methylimidazolium acetate using literature data.

\section{Acknowledgements}

Authors thank the Junta de Castilla y León for funding through the project VA295U14 and the Spanish Economy and Competitiveness Ministry for funding through the project CTQ 2011 14825 - E (Program Explora) C.J. thanks the Spanish Economy and Competitiveness Ministry for the predoctoral grant BES-2011-046496. MDB and AM thank the Spanish Ministry of Economy and Competitiveness for the Ramón y Cajal research fellowship.

\section{References}

[ 1] A. Pinkert, K.N. Marsh, S. Pang, M.P. Staiger, Ionic liquids and their interaction with cellulose, Chem. Rev. 109 (2009) 6712-6728

[ 2] Y. Lv, J. Wu, J. Zhang, Y. Niu, C. Liu, J. He, J. Zhang, Rheological properties of cellulose/ionic liquid/dimethylsulfoxide (DMSO) solutions. Polymer, 53 (2012) 2524-2531.

[ 3] S. Morales-de la Rosa, J. M. Campos-Martín, J. L.G. Fierro, High glucose yields from the hydrolysis of cellulose dissolved in ionic liquids, Chem. Eng. J. 181- 182 (2012) 538- 541

[ 4] K.R. Seddon, A. Stark, M.J. Torres, Influence of chloride, water, and organic solvents on the physical properties of ionic liquids, Pure Appl. Chem. 72 (2000) 2275-2287

[ 5 ] B. Kumar, T. Singh, K.S. Rao, A. Pal, A. Kumar. Thermodynamic and spectroscopic studies on binary mixtures of imidazolium ionic liquids in ethylene glycol, J. Chem.

Thermodyn. 44 (2012) 121-127

[ 6] N.V. Sastry, N.M. Vaghela, P.M. Macwan, Densities, excess molar and partial molar volumes for water+ 1-butyl- or, 1-hexyl- or, 1-octyl-3-methylimidazolium halide room temperature ionic liquids at T= (298.15 and 308.15) K , J. Mol. Liq. 180 (2013) 12-18. [ 7] M. Tariq, F. Moscoso, F.J. Deive, A. Rodriguez, M.A. Sanromán, J.M.S.S. Esperança, J.N. Canongia Lopes, L.P.N. Rebelo, Probing the self-aggregation of ionic liquids in aqueous 
solutions using density and speed of sound data. J. Chem. Thermodynamics 59 (2013) 43-48

[ 8] E. Gómez, B. González, Á. Domínguez, Emilia Tojo, José Tojo, Dynamic Viscosities of a Series of 1-Alkyl-3-methylimidazolium Chloride Ionic Liquids and Their Binary Mixtures with Water at Several Temperatures, J. Chem. Eng. Data 51 (2006) 696-701

[ 9] W. Liu, L. Cheng, Y. Zhang, H. Wang, M. Yu, The physical properties of aqueous solution of room-temperature ionic liquids based on imidazolium: Database and evaluation, J. Mol. Liquids 140 (2008) 68-72

[10] T. Singh, A. Kumar, Thermodynamics of dilute aqueous solutions of imidazolium based ionic liquids, J. Chem. Thermodynamics 43 (2011) 958-965,

[11] N. Calvar, B.Gonzalez, A.Dominguez, J. Tojo, The physical properties of the ternary mixture ethanol+water+1-butyl-3-methylimidazolium chloride at

298.15 K, J. Solution Chem. 35 (2006) 1217-1225.

[12] D. Wu, B. Wu, Y. M. Zhang, H. P. Wang, Density, Viscosity, Refractive Index and Conductivity of 1-Allyl-3-methylimidazolium Chloride + Water Mixture, J. Chem. Eng. Data, 55 (2010) 621-624

[ 13] H. Xu, D. Zhao, P. Xu, Conductivity and viscosity of 1-allyl-3-methylimidazolium chloride+water and+ethanol from 293.15 K to 333.15 K, J. Chem. Eng. Data 50 (2005) 133135.

[ 14] W. Qian, Y.J. Xu, H. Zhu, C. Yu, Properties of pure 1-methylimidazolium acetate ionic liquid and its binary mixtures with alcohols, J. Chem. Thermodyn. 49 (2012) 87-94.

[15] J.M.M. Araujo, A.B. Pereiro, F. Alves, I. M. Marrucho, L.P.N. Rebelo, Nucleic acid bases in 1-alkyl-3-methylimidazolium acetate ionic liquids: A thermophysical and ionic conductivity analysis, J. Chem. Thermodyn. 57 (2013) 1-8.

[16] E. Quijada, S.v.d. Boogaart, J.H. Lijbers, G.W. Meindersma, A.B.d. Haan, Experimental densities, dynamic viscosities and surface tensions of the ionic liquids series 1-ethyl-3methylimizazolium acetate and dicyanamide and their binary and ternary mixtures with water and ethanol at $\mathrm{T}=(298.15 \mathrm{~K}$ to $343.15 \mathrm{~K}) \mathrm{J}$. Chem. Thermodyn. 51 (2012) 51-58

[17] C. Romich, N.C. Merkel, A. Valbonesi, K. Schaber, S. Sauer, T.J.S. Schubert, Thermodynamic Properties of Binary Mixtures of Water and Room-Temperature Ionic Liquids: Vapor Pressures, Heat Capacities, Densities, and Viscosities of Water + 1-Ethyl-3methylimidazolium Acetate and Water + Diethylmethylammonium Methane Sulfonate, J. Chem. Eng. Data 57 (2012) 2258-2264.

[18] S. Fendt, S. Padmanabhan, H.W. Blanch, J.M. Prausnitz, Viscosities of Acetate or Chloride-Based Ionic Liquids and Some of Their Mixtures with Water or Other Common Solvents, J. Chem. Eng. Data 56 (2011), 31-34

[19] C.A. Hall, K. A. Le, C. Rudaz, A. Radhi, C. S. Lovell, R. A. Damion, T. Budtova, M. E. Ries, Macroscopic and Microscopic Study of 1-Ethyl-3-methyl-imidazolium Acetate-Water Mixtures, J. Phys. Chem. B 116 (2012) 12810-12818

[20] A. P. Fröba, M. H. Rausch, K. Krzeminski, D. Assenbaum, P. Wasserscheid, A. Leipertz, Thermal Conductivity of Ionic Liquids: Measurement, Int J Thermophys 31 (2010) 2059-2077 [ 21] B. Mokhtarani, A. Sharifi, H. Reza Mortaheb, M. Mirzaei, M. Mafi, F. Sadeghian, Density and viscosity of pyridinium-based ionic liquids and their binary mixtures with water at several temperatures, J. Chem. Thermodynamics 41 (2009) 323-329

[22] K. Miki, P. Westh, K. Nishikawa, Y. Koga, Effect of an "ionic liquid” cation, 1-butyl-3methylimidazolium, on the molecular organization of $\mathrm{H}_{2} \mathrm{O}$. J. Phys. Chem. B 109 (2005) 90149019

[23 ] H. Rodríguez, J.F. Brennecke, Temperature and Composition Dependence of the Density and Viscosity of Binary Mixtures of Water + Ionic Liquid, J. Chem. Eng. Data 51 (2006) 21452155

[24] L. Grunberg, A.H. Nissan, Mixture Law for Viscosity, Nature, 164 (1949) 799 -800.

[25] B.E. Poling, J. M. Prausnitz, J. P. O’Connell, The Properties of Gases and Liquids, $5^{\text {th }}$ Edition, McGraw-Hill, New York, 2004

[26] K.R. Seddon, A. Stark, M.J. Torres, Viscosity and Density of 1-Alkyl-3methylimidazolium Ionic Liquids, ACS Symp. Ser. 819 (2002) 34-49 